Research Article

www.ijrap.net

\title{
A PILOT STUDY ON CERTAIN YOGIC AND NATUROPATHIC PROCEDURES IN GENERALIZED ANXIETY DISORDER
}

Kshama Gupta*, Prasad Mamidi

Assistant Professor, Department of Kayachikitsa, Parul Institute of Ayurved, Tal. Waghodia, Vadodara, Gujarat, India

Received on: 07/10/13 Revised on: 22/11/13 Accepted on: 02/12/13

\author{
*Corresponding author \\ E-mail: drkshamagupta@gmail.com \\ DOI: 10.7897/2277-4343.04616 \\ Published by Moksha Publishing House. Website www.mokshaph.com \\ All rights reserved.
}

\section{ABSTRACT}

Generalized Anxiety Disorder (GAD) is one of the most common anxiety disorders characterized by persistent worrying, anxiety symptoms, and tension. Most community-based studies place the prevalence in the range of 2 to 5 percent, with a lifetime prevalence as high as 8 percent. Even though previous studies on yoga and naturopathy in anxiety disorders proved effective, there lack proper methodology and they are not specifically focused at GAD. The aim of this study was to assess the efficacy of certain yogic and naturopathic procedures in the management of GAD. A total of 12 patients with GAD satisfying the DSM IV TR diagnostic criteria were selected and allotted in to two groups, Yoga group and Naturopathic group by following randomization method. In Yoga group, various asana's and pranayama were practiced one hour daily for 21 days. In Naturopathy group, full body massage and steam, diaphragmatic breathing and acupressure were done one hour daily for 21 days. Criteria of assessment were based on the scoring of Hamilton Anxiety Rating Scale (HARS). Statistical analysis was done by using paired and unpaired ' $t$ ' test. In Yoga group ( $\mathrm{n}=6$ ), $52.59 \%$ relief was observed $(\mathrm{P}<0.01)$ and in Naturopathy group $(\mathrm{n}=6), 41.61 \%$ of relief was observed $(\mathrm{P}<0.001)$ on the total score of HARS. There was no significant difference $(\mathrm{P}>0.05)$ found in between the two groups. Both Yoga and Naturopathic procedures are effective in the management of GAD. Even though Yoga and Naturopathy interventions proved effective on HARS total score of GAD, Yoga seems to be an attractive option because of its non pharmacological approach, cost effectiveness and international acceptance when compared to the other interventions.

Keywords: Generalized Anxiety Disorder; Hamilton Anxiety Rating Scale; Naturopathy; Yoga

\section{INTRODUCTION}

Generalized Anxiety Disorder (GAD) is one of the most common anxiety disorders characterized by persistent worrying, anxiety symptoms and tension. ${ }^{1}$ A pattern of frequent, persistent worry and anxiety that is out of proportion to the impact of the event or circumstance that is the focus of the worry are the characteristic features of this condition. ${ }^{2}$ Most community-based studies place the prevalence in the range of 2 to 5 percent, with a lifetime prevalence as high as 8 percent. ${ }^{3}$ Even though previous studies reported positive results on the effectiveness of Yoga in anxiety and anxiety disorders, it is not possible to say that Yoga is effective in treating anxiety or anxiety disorders because of their methodological inadequacies, diversity of conditions treated and poor quality of the most of studies. Surprisingly little research has been done on Yoga for clinical anxiety. ${ }^{4}$ Even though there is a popularity in general public regarding the role of complementary and alternative medicine (CAM) treatments in anxiety but there is limited or sometimes contradictory evidence to support their use in the treatment of anxiety disorders. Previous CAM research on anxiety mainly focused on the effectiveness of a single intervention or therapy with no previous studies investigating naturopathic approaches. ${ }^{5}$ By considering all these facts, the present study was planned to evaluate the efficacy of certain yogic and naturopathic procedures in the management of GAD.

\section{Aims and Objectives}

- To evaluate the efficacy of certain Yogic and Naturopathic procedures individually in the management of GAD.

- To compare the efficacy in between Yogic and Naturopathic procedures in the management of GAD.

\section{MATERIALS AND METHODS \\ Participants}

All the patients fulfilling the inclusion criteria were selected irrespective of caste, religion, and economic status with their written consent.

\section{Sample size}

A total of 12 patients were selected and allotted them into two groups, i.e., the Yoga group and the Naturopathy group, with 6 patients in each group.

\section{Age range}

Patients belonging to the age group between 20 and 60 years were selected.

\section{Source of the patients}

Patients were selected from the out patient wing of MPIYNER (Maharshi Patanjali Institute of Yoga and Naturopathy Education and Research), Gujarat Ayurveda University campus, Jamnagar, Gujarat, India.

\section{Inclusion criteria}

- Patients who are fulfilling the DSM - IV TR (Diagnostic and Statistical Manual IV Text revision) diagnostic criteria of GAD (300.02). ${ }^{6}$ 
- Belonging to the age group between 20 and 60 years.

\section{Exclusion criteria}

- Substance induced GAD.

- GAD associated with major organic and psychotic disorders.

\section{Ethical consideration}

The study was cleared by the institutional ethics committee. Written consent was taken from each patient willing to participate before the start of the study. A detailed history of each patient was taken. A general physical examination of all systems was performed. After establishing the diagnosis using DSM IV TR criteria for GAD, the patients were allocated to Yoga and naturopathy groups. Patients were free to withdraw from the study at any time without giving any reason.

\section{Study design \\ Comparative clinical study}

\section{Assessment criteria}

Before treatment and after treatment, total two assessments were carried out. Criteria of assessment were based on the Hamilton Anxiety Rating Scale (HARS). This scale consists of 14 items, each defined by a series of symptoms, scored on a scale of 0 (not present) to 4 (severe), with a total score range of $0-56 .^{7}$

\section{Grouping}

Selected patients were randomly divided in to two groups (Yoga group and Naturopathy group) by following alternate method (first patient in Yoga group, second patient in naturopathy group, third patient in Yoga group like that alternatively).

\section{Intervention in the Yoga group}

The duration of the protocol in this group was 3 weeks. Patients followed the protocol daily 1 hour in the morning (6-7 AM) for 21 days. The protocol started with prayer followed by loosening exercises (stretches and rotations), suryanamaskara's (Sun salutation) and asanas like padmasana (Lotus pose), pawanamuktasana (Leg lock pose), Yoga mudrasana (Psychic union pose), shavasana (Corpse pose), bhujang asana (Cobra pose), shalabh asana (Locust pose), vyaghrasana (Tiger pose) and makarasana (Crocodile pose) were practiced. Asanas were followed by anuloma viloma pranayama (Alternate nostril breathing), and bhramari pranayama (Bee breath). The protocol was not rigidly fixed and the patients were told to practice Yoga asanas and pranayama according to their body's flexibility, convenience, and stamina.

\section{Intervention in the naturopathy group}

Massage of the full body followed by steam, diaphragmatic breathing and acupressure were selected as treatment modalities in the naturopathy group. The duration of the protocol in this group was three weeks. Patients followed the protocol daily for 30 minutes in the morning (7-7.30 AM) and 30 minutes in the evening (6$6.30 \mathrm{PM}$ ) for 21 days. In the morning time, full body massage and steam were done. Total body massage was done with tila taila (sesame oil) followed by application of the steam in steam bath chamber (sitting type). In the evening time, diaphragmatic breathing and acupressure were performed. During diaphragmatic breathing session, it was suggested to the patients to draw air in to the lungs in a way which will expand the stomach and not the chest. It was advised to the patients to perform these breaths as long and slow intakes of air. This session was followed by acupressure, for which particular points were selected: Spirit gate (H 7), Inner gate (P 6), Heavenly rejuvenation (TW 15), Third eye point (GV 24.5), Heavenly pillar (B1 10) and Sea of tranquility (CV 17). ${ }^{8}$

\section{Statistical analysis}

The information gathered on the basis of observations were subjected to statistical analysis in terms of Mean difference, Standard Deviation (S.D), Unpaired " $t$ " test carried out at $\mathrm{P}<0.05, \mathrm{P}<0.01, \mathrm{P}<0.001$. The obtained results were interpreted as follows:

Insignificant $=\mathrm{P}>0.05$

Significant $=\mathrm{P}<0.05, \mathrm{P}<0.01$

Highly significant $=\mathrm{P}<0.001$

\section{Overall effect of therapy}

Overall effect of therapy was estimated as follows:

- $100 \%$ relief - Cured

- $>75 \%$ to $<100 \%$ - Marked improvement

- $>50 \%$ to $75 \%$ - Moderate improvement

- $>25 \%$ to $50 \%$ - Mild improvement

- $0 \%$ to $25 \%$ - Unchanged

\section{Observations}

Maximum number of the patients, i.e., $41.66 \%$ belongs to the age group of 21-30 years (Mean age is 36.25 years), $50 \%$ were married, $41.66 \%$ were graduates, $83.33 \%$ belonging to middle class and $50 \%$ of the patients were male. A majority of the patients, i.e., $58.33 \%$ were having 3-5 years of chronicity.

\section{RESULTS}

In the Yoga group, maximum relief was found in the items like HARS 14 (92.59\%), HARS 4 (75.18\%), HARS 13 (58.65\%), HARS 9 (57.08\%) and HARS 7 $(56.39 \%)$ which measures behavior during interview, insomnia, other autonomic symptoms, cardiovascular symptoms and general somatic symptoms (muscular) respectively and were statistically significant at $\mathrm{P}<0.05$. In the Naturopathy group, maximum relief was found in the items like HARS 6 (71.24\%), HARS 14 (66.66\%), HARS $4(58.65 \%)$, HARS $2(55.33 \%)$ and HARS 9 $(53.70 \%)$ which measures depressed mood, behavior during interview, insomnia, tension and cardiovascular symptoms respectively and was statistically significant at $\mathrm{P}<0.05$. No change $(0 \%)$ was observed in HARS 12 (genito urinary symptoms) in this group. On comparing the effect of therapy in between the two groups, there was no statistically significant difference found in all questions in between the two groups (Table 1). 
Table 1: Comparison of Effect of Therapy on HARS in Between the Two Groups

\begin{tabular}{|c|c|c|c|c|c|}
\hline \multirow{2}{*}{ S. No } & \multirow{2}{*}{ HARS } & Yoga group (n= 6) & Naturopathy group (n= 6) & \multicolumn{2}{c|}{ P value } \\
\cline { 3 - 6 } & & M. Diff with SD* & M. Diff with SD* & t value & * \\
\hline 1 & HARS-1 & $1.33 \pm 0.81$ & $1.66 \pm 1.03$ & 0.63 & $>0.05$ \\
\hline 2 & HARS-2 & $0.83 \pm 0.98$ & $1.66 \pm 1.03$ & 1.45 & $>0.05$ \\
\hline 3 & HARS-3 & $0.33 \pm 0.81$ & $0.66 \pm 0.81$ & 0.71 & $>0.05$ \\
\hline 4 & HARS-4 & $2 \pm 1.54$ & $1.66 \pm 0.81$ & 0.48 & $>0.05$ \\
\hline 5 & HARS-5 & $1 \pm 0.89$ & $0.16 \pm 0.40$ & 2.15 & $>0.05$ \\
\hline 6 & HARS-6 & $0.83 \pm 0.75$ & $1.66 \pm 1.21$ & 1.45 & $>0.05$ \\
\hline 7 & HARS-7 & $1.5 \pm 0.54$ & $0.33 \pm 0.51$ & 4.03 & $<0.01$ \\
\hline 8 & HARS-8 & $1.33 \pm 1.03$ & $0.66 \pm 0.81$ & 1.28 & $>0.05$ \\
\hline 9 & HARS-9 & $1.33 \pm 0.81$ & $1.16 \pm 0.75$ & 0.38 & $>0.05$ \\
\hline 10 & HARS-10 & $0.66 \pm 0.81$ & $0.83 \pm 0.75$ & 0.38 & $>0.05$ \\
\hline 11 & HARS-11 & $1.33 \pm 0.51$ & $0.66 \pm 0.81$ & 1.76 & $>0.05$ \\
\hline 12 & HARS-12 & $0.66 \pm 1.03$ & $0 \pm 0$ & 1.60 & $>0.05$ \\
\hline 13 & HARS-13 & $1.66 \pm 1.36$ & $1.66 \pm 1.03$ & 0 & $>0.05$ \\
\hline 14 & HARS-14 & $2 \pm 0.63$ & $1 \pm 1.09$ & 2 & $>0.05$ \\
\hline
\end{tabular}

Table 2: Overall Effect of Therapy Based on Relief on HARS

\begin{tabular}{|c|c|c|c|c|}
\hline \multirow{2}{*}{ Effect } & \multicolumn{2}{|c|}{ Yoga group (n=6) } & \multicolumn{2}{c|}{ Naturopathy group (n= 6) } \\
\cline { 2 - 5 } & No. of Patients & Percentage & No. of Patients & Percentage \\
\hline Cured & 0 & 0 & 0 & 0 \\
\hline Marked improvement & 1 & $16.66 \%$ & 0 & 0 \\
\hline Moderate improvement & 2 & $33.33 \%$ & 3 & $50 \%$ \\
\hline Mild improvement & 2 & $33.33 \%$ & 2 & $33.33 \%$ \\
\hline Unchanged & 1 & $16.66 \%$ & 1 & $16.66 \%$ \\
\hline
\end{tabular}

\section{Effect of therapy based on total score of HARS}

After treatment period, the \% of relief on HARS total score was $52.59 \%(\mathrm{P}<0.01)$ in the Yoga group and $41.61 \%$ in the Naturopathy group $(\mathrm{P}<0.001)$. On comparing the effect of therapy on HARS total score in between two groups, it was found that the mean difference was 16.83 in the Yoga group with $\mathrm{SD} \pm 9.66$ and in the Naturopathy group the mean difference was 12.83 with $\mathrm{SD} \pm 6.76$. The " $t$ " value was found to be 0.84 which was statistically insignificant $(\mathrm{P}>0.05)$. There were no significant side effects or drop outs reported during the course of treatment. The overall effect of therapy based on HARS was calculated after treatment. It was found that in Yoga group maximum patients (66.66 $\%$ got mild and moderate relief whereas in naturopathy group maximum patients $(50 \%)$ got moderate relief (Table 2).

\section{DISCUSSION}

Results of this study indicate a significant reduction in anxiety level from the use of either Yoga or naturopathy intervention. Comparatively, Yoga treatment showed a clinically significant improvement (not statistically) in anxiety. Yoga could perhaps be causing better anxiety control. This assertion is supported by several studies. Measurable decline in anxiety scores could be achieved as early as within 10 days if the patients adopt healthy life style interventions consisting mainly of asanas, pranayama, and relaxation techniques. Others have reported that Yoga promotes well-being, improves quality of life, and has an anti-depressant effect. Relaxation induced by meditation helps to stabilize the autonomic nervous system with a tendency toward parasympathetic dominance. Additional mechanisms contributing to a state of calm alertness includes increased parasympathetic drive, calming of stress response systems, neuroendocrine release of hormones, and thalamic generators. . Various asana's, pranayama's selected in the present study are known to be effective in managing anxiety and nervous tension. ${ }^{10}$ In present study also Yoga intervention provided similar results especially in anxiety, insomnia, autonomic, cardiovascular and muscular symptoms. Naturopathic medicine (also known as naturopathy) is a school of medical philosophy and practices that to seek improvement in health and treat disease chiefly by assisting the body's innate capacity to recover from illness and injury. This alternative medical system of care employs the use of many CAM therapies including acupuncture, herbal medicine, osteopathy, nutrition, homeopathy, and lifestyle counseling in a combined manner to address the underlying cause of disease. No previous studies have investigated the impact of a naturopathic approach for anxiety. ${ }^{11}$ Diaphragmatic breathing applied in naturopathy session, in present study, has been shown to reduce anxiety levels and improve managing capability in stressful situations. ${ }^{12}$ The acupressure points incorporated in naturopathic session were proved to be effective and recommended in the treatment of anxiety and nervousness. ${ }^{13}$ Naturopathy group provided mild to marked improvement in the conditions like depressed mood, behavior, insomnia, tension and cardiovascular symptoms in the present study. As it is a pilot study, further studies are needed with large sample.

\section{CONCLUSION}

Both Yoga and naturopathy interventions were proved effective in the management of GAD on HARS scoring. Even though there was no statistically significant difference in between both groups, Yoga would be an attractive option in treating GAD, because it is nonpharmacological, has minimal adverse effects if practiced in a proper way, cost effective and enjoys international acceptance compared to other interventions. 


\section{REFERENCES}

1. Wittchen HU. Generalized Anxiety Disorder: Prevalence, Burden, and Cost to society. Depression and Anxiety 2002; 16: 162. http://dx.doi.org/10.1002/da.10065 PMid:12497648

2. Sadock BJ, Sadock VA. Kaplan and Saddock's Comprehensive Textbook of Psychiatry. $8^{\text {th }}$ edition. Lippincott Williams and Wilkins; 2005. p. 1777.

3. Sadock BJ, Sadock VA. Kaplan and Saddock's Comprehensive Textbook of Psychiatry. $8^{\text {th }}$ edition. Lippincott Williams and Wilkins; 2005. p. 1779.

4. Kirkwood G, Rampes H, Tuffrey V, Richardson J, Pilkington K Yoga for anxiety: a systematic review of the research evidence. Br J Sports Med 2005; 39: 884-891. http://dx.doi.org/10.1136 bjsm.2005.018069 PMid:16306493 PMCid:PMC1725091

5. Cooley K, Szczurko O, Perri D, Mills EJ, Bernhardt B, et al. Naturopathic Care for Anxiety: A Randomized Controlled Trial PLoS ONE 2009; 4: 6628. http://dx.doi.org/10.1371 /journal.pone.0006628 PMid:19718255 PMCid:PMC2729375

6. American Psychiatric Association. Diagnostic and Statistical Manual of Mental Disorders - Text Revision (DSM-IV-TR). $4^{\text {th }}$ edition. New Delhi: Jaypee Publications; 2000. p. 476

7. Available from: http://www.cnsforum.com/clinicalresources /ratingscales/ratingpsychiatry/anxiety/
8. Available from: http://www.innerpath.com.au/acupuncture/ Acupressure-Treat.html

9. Dhikav V, Karmarka GM and Anand KS. Yoga in generalized anxiety disorder: A comparative trial with fluoxetine. J Sex Med 2007; 4: 1730. http://dx.doi.org/10.1111/j.1743-6109.2007.00603.x PMid: 17888067

10. Swami Satyananda Saraswati. Asana Pranayama Mudra Bandha. $3^{\text {rd }}$ edition. Munger: Yoga publications trust; 2006. p. 540.

11. Smith MJ, Logan AC. Naturopathy. Med Clin North Am 2002; 86: 173-184. http://dx.doi.org/10.1016/S0025-7125(03)00079-8

12. Somer E, Tamir E, Maguen S, Litz BT. Brief cognitive-behavioral phone based intervention targeting anxiety about the threat of attack: a pilot study. Behav Res Ther 2005; 43: 669-679. http://dx.doi.org/10.1016/j.brat.2004.05.006 PMid:15865920

13. Available from: http://www.innerpath.com.au/acupuncture/ Acupressure-Treat.html

Cite this article as:

Kshama Gupta, Prasad Mamidi. A pilot study on certain yogic and naturopathic procedures in generalized anxiety disorder. Int. J. Res Ayurveda Pharm. 2013;4(6):858-861 http://dx.doi.org/10.7897/2277$\underline{4343.04616}$ 